moting acceptance of improved diets, are dealt with in successive chapters.

The symposium agreed that the newer knowledge derived from research in the behavioural sciences must be taken into account when planning for the educational aspects of canteen operation. It was suggested that much more attention should be directed to scientific research on food habits and food preferences among specific groups of workers in particular areas, on rates and channels of change in nutritional and diet practices, the effectiveness of different types of activities, and the results of educational methods and materials used. It was considered that carefully planned training in educational methods of techniques, as well as in relation to the psycho-social and cultural determinants of human behaviour about nutrition, should be included in all professional courses for people who would be responsible at a relatively high level for the management of industrial canteens.

Participants at the symposium urged the need for more exchange of information and better distribution of current literature. A suggestion was strongly supported that an international organization, possibly the Food and Agriculture Organization, should establish a clearing house for current literature, research and information on the nutrition of workers. It was also recommended that a joint study group of specialists in industrial feeding and eantecn management should be sponsored by the three Specialized Agencies. Such a study group, meeting at regular intervals, could co-ordinate and, where necessary, sponsor investigations and research in industrial feeding and suggest suitable planning and methods of research into the various aspects of industrial feeding. These might include food consumption and nutritional status of workers; times and amounts of food required by workers in relation to the type of work and the work environment; the influence of time-intervals between meals, length of meal periods and amount of food consumed on workers' efficiency; the psycho-social, socio-economic and cultural patterns that lead to the use or disuse of industrial feeding units; new foods and food processing methods; kitchen planning and lay-out in relation to work efficiency, quality of food and economic produetion; kitchen equipment, its use and upkeep; training and education of managers, supervisors and workers; education in nutrition for industrial workers. It was also suggested that the group could study with specialists, the Governments concerned, and organizations of employers and workers any additional problems related to industrial feeding and encourage the development of a uniform system of terminology to facilitate exchange of information in this field.

\title{
NATIONAL COAL BOARD MINING RESEARCH ESTABLISHMENT
}

$\mathrm{T}$ HE Mining Research Establishment held open days during July 19-23, of which three days were reserved for overseas delegates to the fourth International Mining Congress and two days for visitors from Great Britain. The demonstrations illustrated the wide application of the research results to mining problems.

Much effort has been put into supporting the National Coal Board's drive to offset by instrumentation the reductions in manpower expected in the future. On the coal face, automatic steering of the getting machine to keep it in the coal poses problems analogous to those met in the guided-missile field. Information as to the position of the machine is supplied by a nucleonic device that measures the thickness of coal left above or below the machine in terms of the back-scatter of gamma rays directed into the floor or roof from a radioactive source. The vertical orientation of the machine is given by a tilt transducer, and the two signals are fed into an electronic control unit operating the steering jacks. The actual system required depends on the delays inherent in the input and output sides and on the geometry of the machine, characteristics which vary with each type of machine. A certain amount of information has to be obtained from full-scale field observation, but the amount of field work is kept within practical bounds by simulating transducer outputs and machine performance on an analogue computer.

Remote-control techniques have already been successfully applied experimentally on the coal face to control both getting machine and roof supports, and the Mining Research Establishment is heavily involved in the extension at Bevercotes Colliery of analogous techniques to give remote control of other sectors of the mine and to communicate production information to central points underground and on the surface as an aid to management.

Almost all underground instrumentation, whether for remote control, monitoring or research, must be intrinsically safe, that is, incapable under any conditions of operation or failure of producing a spark of energy sufficient to ignite a methane-air mixture. Research at the Mining Research Establishment on inductive breaksparks has shown that ignition can be brought about at an energy-level one-fifth of that hitherto accepted as the minimum and of the same order as that previously asso. ciated only with capacitative circuits. This lends support to the minimum energy concept of ignition which can be applied to the design of intrinsically safe circuits. Two new protective devices, the Zener diode and the surge arrestor, have been introduced into this field.

Experiments on the mode of breakage of rock and coal under simple forces or when attacked by tools have led to a theory of breakage based on brittle fracture. The deductions have led to a rationalization of the design of mining tools and machinery to give faster production for less power with the added benefits of a larger product and less dispersion of respirable dust and firedamp. Systematic study of the forces and movements around mine workings is suggesting improvements in the design and use of supports. Comparison of results obtained with those reported elsewhere indicates that many of the basic phenomena follow the same laws in all coal-fields of the world.

A considerable amount of research is directed to increasing the safety of the atmosphere in the mine by reducing the dangers from firedamp accumulations and from the respirable $(1-5 \mu)$ dust which causes pneumoconiosis. Airflow near the coal face is studied using scale models in which the flow patterns are made visible by illuminating tracer particles suspended in water. Results have been verified underground by ventilation surveys and by the use of tracer gases and smoke. Tracer gas is also one of the means used for studying the dispersion of firedamp from the coal seam. The Mining Research Establishment has pioneered the development of instruments for sampling respirable dust. The 'long-running thermal precipitator' samples the respirable fraction of the dust in the air during a full shift. The sample is usually evaluated by counting, but an optical densitometer has been designed which gives a rapid evaluation either in number of particles or mass. A gravimetric dust sampler collects a sample, again during a whole shift, on a fibreglass filter. Accuracy of evaluation is considerably higher than that with the 'long-running thermal precipitator' and mass is probably a more important parameter clinically than particle count. Research on dust dispersion and suppression has shown the overriding importance of good design, maintenance and use of machinery so as to minimize dust formation and 
dispersion. The most effective ways of using water for dust suppression have been demonstrated and the use of exhaust ventilation with filtration is being studied.

Each year the National Coal Board spends something like $£ 100$ million on metal products: working out proper specifications of the materials involved is an important part of the work at the Mining Research Establishment. Of equal importance are investigations to ensure that advances in metallurgical science are applied to modern mining techniques. Corrosion can cause serious losses and mine waters vary widely in $p \mathrm{H}$ and salinity. Research into the resistance of different steels to the various contaminations and the protection afforded by metallic and other coatings is aimed at minimizing corrosion losses. Oil-in-water and invert emulsions are being introduced underground as fire-resistant substitutes for hydraulic oils. The stability and corrosion-inhibiting properties of these fluids are therefore being studied in addition to the relationship between their physical properties and performance. Aqueous glycols and phosphate esters are also being examined in this context.

A requirement peculiar to steels for mine supports is that they shall withstand repeated slow plastic bending; safety demands that neither initially nor after such treat. ment shall they be liable to brittle fracture. The value in these conditions of heat-treated carbon manganese steels has been established and means are being sought of further increasing strength without embrittlement in a continual effort to reduce the size and weight of mining equipment. The advantages and possible dangers of the use of highstrength steels, including spring steels, are being studied with the same objective. The fatigue properties of alloy steels for suspension gear have been determined with and without stress raisers. From this work the degree of advantage of alloy steels over manganese steel as used at present has been determined.

Cemented carbides and other hard facings are being studied to establish the best compromises for different mining tools between abrasion- and chipping-resistance. An electron microscope is being used to further this work. Methods of brazing the carbide tips on to the tools are included in the study.

Nearly 8 million yards of conveyor belting is used in British collieries and specification tests have been evolved for fire-resistant belting. The tests include not only fire resistance and performance but also surface electrical resistance in order to ensure that static charges do not build up on the surface of the plastic (polyvinylchloride), which has replaced flammable rubber in underground belting. The same problerns of fire-resistant and anti-static properties arise with all plastics used underground and there is a steady stream of articles arriving at the Mining Research Establishment for examination as underground applications are found for these new materials.

Conveyor belting has improved enormously in strength over recent years; it has been necessary to improve methods of jointing. A new type of fastener has been devised at the Mining Research Establishment which gives a performance several times better than fasteners at present in use, and work is continuing further to improve jointing methods. Simultaneously the fastener-holding properties of belts are being examined and the effect of varying the fabric in the carcass is being determined.

C. S. Makower

\title{
DEFORMATION OF SOLIDS BY THE IMPACT OF LIQUIDS, AND ITS RELATION TO RAIN DAMAGE IN AIRCRAFT AND MISSILES, TO BLADE EROSION IN STEAM TURBINES, AND TO CAVITATION EROSION
}

\author{
By Dr. J. H. BRUNTON, Dr. J. E. FIELD and G. P. THOMAS \\ Physics and Chemistry of Solids, Cavendish Laboratory, Cambridge
}

\begin{abstract}
A DISCUSSION on "The Deformation of Solids by the Impact of Liquids" was held by the Royal Society on May 27. In his opening remarks, Dr. F. P. Bowden, who had organized the discussion, stated that the meeting would begin by considering the physics of liquid impact and the nature, magnitude and duration of the stresses which are produced when a solid is struck by a drop of liquid. Even with moderate impact velocities the pressures developed in the solid are considerable, and at high velocities the shock pressures are very great indeed and are sufficient to produce deformation of the strongest solids. These observations have a bearing on three technical problems which are of considerable importance at the present time. The first is the damage causeu to a high-speed aircraft or missile when it strikes a raindrop. The second is the erosion of turbine blades rotating at high speed in wet steam. The third is the damage produced by 'cavitation' in liquids. There is now evidence that the stress due to liquid impact is a common factor in all three of these processes. One interesting development of this work is that liquid impact is being used as a practical method for 'cutting' or fracturing solids.

In the section on the physics of impact, papers by Dr. J. H. Brunton and Dr. J. E. Field (Cavendish Laboratory, Cambridge) described investigations of the high-speed impact of cylindrical and spherical drops on hard surfaces. At velocities in the region of $1,000 \mathrm{~m} / \mathrm{sec}$, they found that the impact pressures reached values of about $370 \mathrm{~kg} \mathrm{~mm}$, a figure appreciably greater than the strength of many
\end{abstract}

common structural materials. They found that the behaviour of the drop on impact was adequately described by the 'water-hammer' equation. 'The main characteristics of this behaviour were an initial short duration (1-2 $\mu \mathrm{sec})$ water-hammer pressure and a high-speed flow from under the imparting drop. The large magnitude and short duration pressure peak gave the drop impact an 'explosive' character and the high-flow velocities led to erosion at surface discontinuities in the target specimen. In brittle materials the impact characteristics gave rise to ring fracture patterns, and in metals to smooth depressions with eroded edges. In thin-plate specimens 'scabbing' (spalling) occurred near surfaces where the compression wave was reflected. The influence of surface flaws on failure in brittle materials was described.

An interesting account of the high-speed jets which arise when concave liquid surfaces collapse under pressure from behind was given by Dr. F. P. Bowden (Cavendish Laboratory, Cambridge). Examples were shown of liquid Munroe jets, and of jets formed in collapsing cavities and between coalescing drops. The implications of jet formation in cavitation were discussed in a later paper by $\mathrm{Dr}$. T. Brooke Benjamin and Prof. A. T. Ellis.

Sir Geoffrey Taylor (Cavendish Laboratory, Cambridge) described an investigation of the problem of the oblique impact of a liquid jet on a plane surface. The transformation of the jet into a thin sheet was examined and compared with experiment. The maximum steady-state pressure was always the stagnation pressure, but it 